\title{
An Assessment of Student Perceptions and Responses to Frequent Low-stakes Testing in Introductory Sociology Classes
}

\author{
Zachary Schrank'
}

\begin{abstract}
Common concerns for many instructors of introductory college courses are that their students do not prepare for or attend class, are minimally engaged, and exhibit poor reading comprehension and writing skills. How can instructors respond to these challenges? Research finds that frequent testing improves the learning outcomes of students. Can it motivate better studying habits and expand their engagement with the class? This article assesses an experimental design comparing student perceptions and responses to low-stakes, daily written exams versus dispersed, high-stakes major exams in two introductory sociology classes. The objective of the experimental design was to test how daily exams incentivize compliance with assigned readings and class attendance as well as enhance students' experience and engagement within the class. My findings suggest that low-stakes frequent exams are a more effective method to generate these outcomes compared to infrequent high-stakes exams.
\end{abstract}

\section{Keywords}

introduction to sociology, frequent examination, low-stakes testing, student engagement

Introductory sociology courses are widely admired by students, instructors, and administrators. They not only offer a broad overview of the essential elements of the field but also serve a wide cross-section of college students for general education purposes. Introductory sociology classes can also be exciting because they challenge anecdotal explanations for human behavior and open new ways of perceiving the social world (Greenwood and Howard 2011). For these reasons, they are great classes to facilitate student assimilation into college life and the development of critical thinking skills. There are also many challenges, however, to effective teaching and learning in introductory sociology classes.

One ongoing challenge reflects the substantial changing composition, demographics, and class size of incoming college cohorts. Higher education has expanded dramatically, and the percentage of high school graduates who go to college continues to increase. Introductory classes are on the front lines of these changes as they absorb a wide spectrum of the student body, especially at large public institutions. As many new students arrive to college, introductory classes often become comprised of many underprepared students (Doubleday 2013; Gabriel 2008; Weimer 2002). A sizable percentage of incoming students are not familiar with the demands of higher education and effective study habits for exams in their new learning environment (Sanoff 2006). Inevitably, many new students get lost and left behind in the transition largely because they do not know how to adapt to the rigors of college (Gabriel 2008; Kuh et al. 2007; Wankat 2002).

'Indiana University South Bend, South Bend, IN, USA

\section{Corresponding Author:}

Zachary Schrank, Department of Sociology and Anthropology, Indiana University South Bend, 1700 Mishawaka Ave., South Bend, IN 46634, USA.

Email: zschrank@iusb.edu 
In order to handle large and diverse classes, introductory courses are often designed with major midterm and final exams as the standard method for assessment and point allocation over a semester. This format makes sense given the larger enrollment numbers typical of these courses. The time and organizational constraints that result from high student-to-teacher ratios incentivize grading efficiency. Research, however, challenges the usefulness of infrequent high-stakes exams on testing depth and retention of learning and, conversely, has demonstrated that frequent low-stakes testing is a more effective model (Bangert-Drowns, Kulik, and Kulik 1991; Pennebaker, Gosling, and Ferrell 2013; Siadat, Musial, and Sagher 2008).

In this study, I offer a testing design structured around daily low-stakes written examinations for introductory sociology classes as an alternative to the major midterm and final model. During the Spring 2015 semester, I conducted an experiment with two introductory sociology classes to assess how students perceived and responded to frequent low-stakes tests. The control class took three major exams spread out five weeks apart, and the experimental class instead took small daily exams at the beginning of the period. Findings suggest that students in the experimental class not only prefer daily low-stakes testing but are also more engaged with the course material both in and outside of the class. Daily low-stakes testing was a success in these regards and potentially worthy of greater implementation in introductory sociology courses. The tradeoff with frequent testing, however, is that the additional time necessary for grading further burdens instructors who may find themselves overloaded with large classrooms, extensive responsibilities, and fewer resources (Lucal 2015). Therefore, I offer suggestions for how variations of frequent testing could be implemented into large classrooms without prohibitively increasing the time commitments for grading.

\section{LITERATURE REVIEW}

With the changing environment of higher education and the reality of high student-teacher ratios, it is in the interest of sociologists to adapt their teaching practices and strategies to make the classroom a vibrant atmosphere that is conducive to student learning. For years, scholars and teachers have been studying ways to enhance the learning process as our classrooms evolve. Novel techniques have been implemented, researched, and debated as we attempt to uncover the best practices that work in various contexts and settings to not only teach well but to produce effective learning outcomes (Barr and Tagg 1995). With introductory classes, however, the challenges remain immediate and wide. Developments in the science of testing and learning are uncovering effective testing strategies that assist students as they acclimate to college life.

One way to reorient introductory sociology classes that can be helpful to students is to approach testing itself as a technique for promoting learning (Jacobs and Chase 1992; Zipp 2007). Benedict Carey (2014:83) argues, "A test is not only a measurement tool, it alters what we remember and changes how we subsequently organize that knowledge in our minds. And it does so in ways that greatly improve later performance." Brown, Roediger, and McDaniel (2014:19) even describe testing as "a tool for learning." Testing has been shown to be a useful learning tool because it forces students into the active practice of retrieving studied information, directly exposes strengths and weaknesses, and brings to attention specific areas where one can improve future performance.

Not all tests are alike, though. An adjustment instructors of introductory sociology could make to address challenges in their classes is to implement test designs that more accurately reflect the way our minds process and retain new information. Researchers have found empirical evidence that frequent low-stakes testing is a more effective way to boost student learning and knowledge retention over time compared to infrequent high-stakes testing (Bangert-Drowns et al. 1991; Dunlosky et al. 2013; Kika, McLaughlin, and Dixon 1992; Kling et al. 2005; Leeming 2002; McDaniel et al. 2011; Pennebaker et al. 2013; Siadat et al. 2008). One explanation for this finding is that new and often unprepared college students need persistent incentives to study foundational concepts and be held accountable throughout the semester, and frequent low-stakes tests best match these needs. Recent cognitive science suggests that learning is optimized when students are frequently and repetitively exposed to new ways of thinking that demand ongoing examination through practice and retrieval (Halpern and Hakel 2003). Constant exposure and practice with new concepts provides the opportunity for learners to adapt their thinking, incorporate ideas, and retain new information steadily over the duration of a semester (Brown et al. 2014).

In a recent study conducted at the University of Texas at Austin, researchers tested the effectiveness of 
frequent examinations compared to infrequent exams in two introductory psychology classes with identical exam and quiz questions (Pennebaker et al. 2013). In two control sections, students used a standard textbook and took four large class-long exams during the semester. In two experimental sections, students read from online sources instead of a textbook and took much smaller 10-minute quizzes at the beginning of each class with wifi-enabled devices. The researchers found that students in the experimental conditions performed better on the quizzes and retained more course information by the end of the semester compared to their peers in the control classes. Frequent testing also correlated with a reduction in the scoring performance gap between students of high and low socioeconomic status (Pennebaker et al. 2013). The researchers conclude that frequent testing is beneficial because it provides "targeted, structured feedback" to students "so they can adjust their learning and studying strategies in time to improve their performance" (Pennebaker et al. 2013:1).

Three problems associated with the high-stakes exams as the only method for testing in introductory classes stand out. First, attendance tends to gradually drop off throughout the semester when students are not expected to contribute or perform regularly within class (Gabriel 2008). When the major bulk of students' grades are derived mainly from a midterm or final, many students lose interest in the course or find coming to class unnecessary and earn lower grades (Brocato 1989; Friedman, Rodriguez, and McComb 2001). Therefore, a common concern of instructors who have been entrusted to teach introductory sociology is that many students are not prepared, engaged, or present in class.

Second, and unsurprisingly, a disheartening percentage of students do not read assigned class material unless they are given a clear incentive to do so. Researchers have consistently found that more than 70 percent of students do not complete assigned readings for regular class days (Burchfield and Sappington 2000; Marshall 1974; Self 1987). Sporadic or infrequent examinations make it possible for students to procrastinate or avoid reading study material until the absolute last moment possible. Without doing the reading throughout the semester, students retain less long-term information and make fewer connections between concepts that cumulatively develop on a weekly basis. Compounding this problem, many students who enter introductory classes are unfamiliar with critically examining text and struggle with writing (Leamnson 1999; Sanoff 2006). If students are not forced to read regularly, attend class, and be tested often, they are unlikely to receive the feedback needed to make improvements and develop skills to succeed in college (Brown et al. 2014).

The culmination of these two problems leads to a third problem associated with high-stakes testing. Many students experience an enormous amount of test anxiety when preparing for high-stakes, major midterm and final exams (Rosenfeld 1978). Procrastination, low attendance, and a lack of engagement in the classroom compounded with looming exam dates on the course calendar lead to significant difficulties for a sizable percentage of unprepared students. Remedying these problems requires that we build pedagogical practices into courses that reflect new insights into how we learn and the conditions that inspire the desire to learn.

Another reason frequent low-stakes testing may be more effective for learning retention is because students often cram before high-stakes exams. Many students do not develop the discipline to read and prepare on a consistent basis ahead of exams early in their college career (Gabriel 2008). While useful in the short term, cramming does not result in the same type of long-term operational memory, and information is usually lost quickly (Brown et al. 2014; Carey 2014; Cepeda et al. 2008). It also does not generate the type of deep learning compared to frequent small-stakes exams. When preparing for high-stakes exams, such as a midterm or final, it is common for students to procrastinate and study the bulk of material at the last minute. Students might drift for weeks between major exams without being held accountable. By the time the major exam arrives, many students only maintain a superficial or topical level of understanding of course material and concepts. Without adequately reading, practicing, and repeatedly working through concepts incrementally, students retain less knowledge over time. Instead, spacing out studying in shorter increments over a longer period of time helps the brain to generate deep learning that actually lasts and can be transferred to understanding and mastering other concepts (Brown et al. 2014).

These findings related to frequent examination have established the benefits of effective testing designs to generate positive learning outcomes. But instructors should also consider other ways that frequent testing might broadly benefit to our students. Therefore, this study focuses on the useful application of frequent low-stakes testing beyond learning retention and considers how students perceive and respond to it in ways that might positively affect other dynamics in and out of the introductory classroom. 


\section{RESEARCH QUESTIONS AND METHODS}

Empirical evidence demonstrates that frequent testing supports higher learning outcomes. Does it positively contribute to other aspects of the class? In order to perform well in a class throughout a semester with frequent exams, students need to regularly read assigned study material, attend class, and be engaged with lectures and discussions. How do students respond to this design? Do they feel positive about daily exams or prefer infrequent high-stakes exams? This study seeks to answer these questions by measuring student perceptions of frequent testing as well as assessing the qualitative nature of the classroom with this type of exam design.

In order to understand how students respond to and perceive different testing structures, I conducted an experiment with two sections of introductory sociology at a public university. These class sections met twice per week on the same day with 40 students enrolled in each. Student composition was nearly the same in both the control and experimental classes. Ninety percent of the students in experimental section were either first-year or lower-level students, and 76 percent of the students in the control section were either first-year or lower-level students. Assigned readings were identical and typically ranged from 20 to 30 pages per class from a textbook, book chapters, or journal articles. Both sections also had the same homework assignments that cumulatively integrated multiple developing concepts over the semester. The major difference was that the control section was structured with a traditional high-stakes testing model with three major exams at five-week intervals during the semester. Each of these major exams were worth 20 percent of the students' final grade, totaling 60 percent of the points available. The experimental section was structured with daily low-stakes exams over 27 class meetings that were graded after each class. Each exam was worth about 3 percent of their final grade, cumulatively totaling 80 percent of the possible points. Students from both sections were informed at the beginning and end of the semester about this research with a study information guide. I explained that research suggested that exams are effective tools for learning and that students in this project would help me identify the effectiveness of testing frequency.

Because frequent writing is the best way to enhance writing skills and assess students' understanding of concepts, I designed exams that were entirely writing based for both the control and experimental sections. Studies suggest that learning and critical thinking is enhanced when students regularly retrieve information and articulate their ideas in writing, but many students come to college with very poor writing skills (Elbow 1997; Graham and Hebert 2010; Grauerholz, Eisele, and Stark 2013; Greenlaw 2003; Quitadamo and Kurtz 2007). Therefore, it is important that writing instruction and frequency occur early and often at college, especially in sociology classes where so much of what we expect students to learn is conceptual (Atkinson and Lowney 2016). To become proficient writers, however, students must also be active readers and regularly read the material assigned in their courses. One approach that has been demonstrated to motivate students to read is to get them accustomed to taking regularly scheduled announced quizzes (Hatteberg and Steffy 2013). When students expect quizzes and know they are part of their regular performance in class, they are more likely to do assigned reading. By incorporating frequent low-stakes writing examinations into a classroom, an instructor structures two important activities for introductory students: forcing accountability to assigned reading and extended opportunities to enhance basic writing skills.

In the control section, I designed each exam with a combination of questions to be answered in short-response (two or three sentences), mediumlength response (five to six sentences), and an essay format (approximately 15 sentences) over the duration of the 75-minute class period. In the experimental section, I comprised each exam with a short essay question based on the assigned reading to be answered in at least five to six sentences. I also asked the students to respond to a second question based on previous lecture material in a two- or three-sentence response. The students in the experimental section were given 12 minutes to complete these responses at the beginning of each class. Therefore, another difference between the designs of the exams in these two sections was the duration of time over the semester that students spent writing their responses in class. In the control class, the total amount of in-class exam writing was 225 minutes. In comparison, in the experimental section students spent a total of 324 minutes writing their responses on exams.

The nature of the exam questions for both sections was very similar, but questions were not identical. Because we only devoted 12 minutes of each class in the experimental section to examination, students could not write full essays that would 


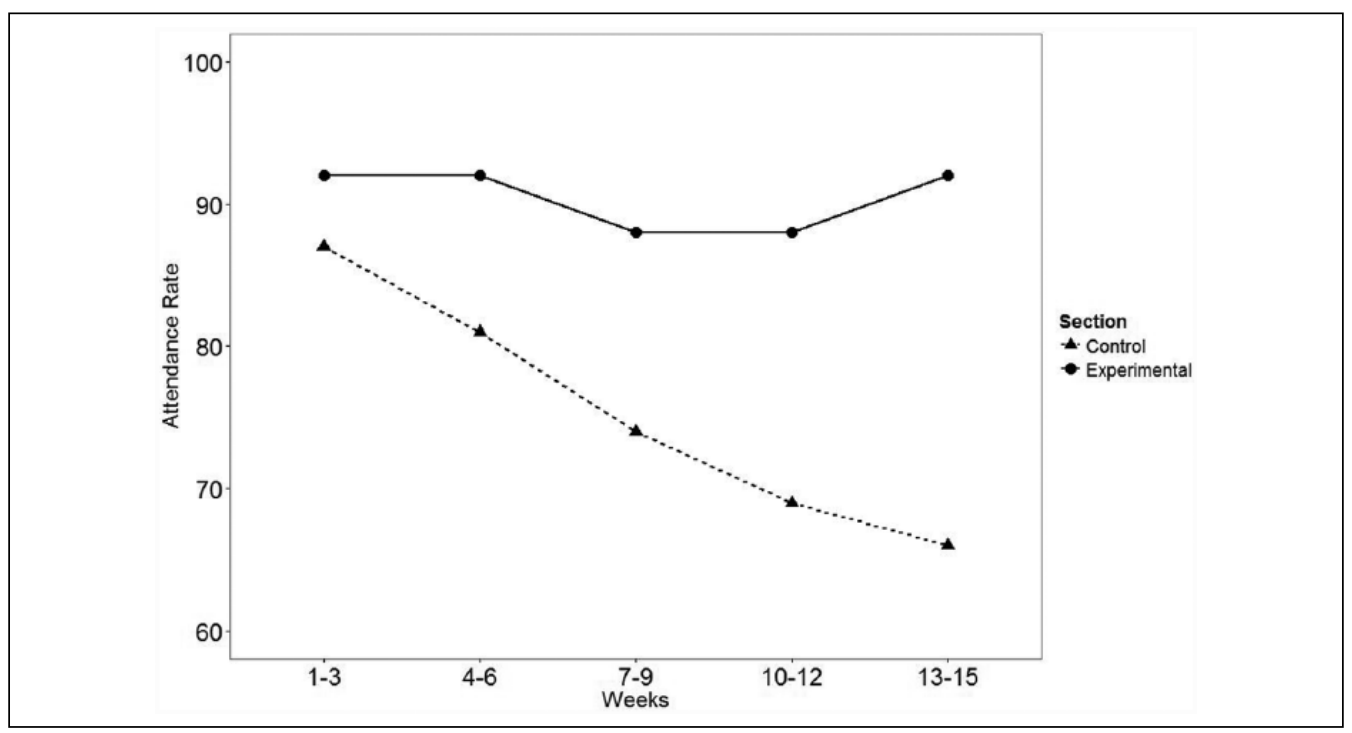

Figure I. Attendance rate of each section.

typically take 30 to 45 minutes to answer during exam days in the control section. I designed questions for both sections, however, around concepts that I intended to be answered with varying degrees of complexity. By the end of the semester, all students had responded to questions regarding identical class content.

Students from both sections had the opportunity to take an optional survey about their experiences with the class. The questions in the survey were designed using a Likert scale to measure the degree to which they positively and negatively perceived various outcomes directly related to the course. This survey was administered online and allowed students to rate their interest on the class in particular and sociology in general, the likelihood that they would take more sociology classes in the future, and their overall satisfaction with the formats of exams and lectures. The survey also provided an opportunity for students to assess their own learning, critical thinking, and writing skills over the semester. The response rate was high, with approximately 85 percent completing the evaluation and survey for each section.

Students were also given the opportunity to complete a standard course evaluation administered by the university at the end of the semester. These evaluations provided students with the space to write comments regarding their perceptions of tests, the instructor, and the structure of the course. The response rate from the control section was 75 percent, and from the experimental section it was
85 percent. Therefore, between the optional surveys and standard evaluations, I collected both qualitative and quantitative measures of student perceptions.

\section{RESULTS}

There were several positive outcomes associated with frequent low-stakes testing. Students performed better on their exams in the experimental section with an average of 82 percent $\mathrm{B}-$-, whereas the control section averaged a 79 percent $\mathrm{C}+$. This was expected, as it supports many previous studies regarding learning retention associated with frequent low-stakes exams. Positive outcomes, however, extended beyond learning and test performance. Attendance and classroom engagement remained strong in the experimental section. On the survey and evaluation, students from the experimental section also rated various aspects of the course higher than their counterparts in the control section.

\section{Attendance, Reading Compliance, and Classroom Engagement}

Students in the experimental section consistently attended class regularly at a rate that hovered around 90 percent. In contrast, the attendance rate began to drop off precipitously in the control section to around 66 to 73 percent midway through the semester (see Figure 1). Having a full class with high attendance noticeably changed the dynamic of 
lecture and class discussion. When nearly all students were present, they were more likely to share thoughts and opinions with one another. Students could also depend on partners in their groups to not only be present but also be prepared to engage in activities, debates, and conceptual reviews.

Conversely, the gradual attrition in attendance in the control class fostered a more ambivalent class atmosphere. Students would sometimes take note of the fact that a sizeable portion of their classmates had vanished toward the end of the semester. I would overhear students say, "Where did everyone go?" and "I guess my group isn't here today." It became apparent that the mood of this class became less enthusiastic because a large percentage of other students simply stopped attending regularly. In the evaluations, students had the opportunity to comment on "suggestions [to] improve the course." When considering this problem of attendance rates, one student from the control section suggested the instructor needed to "find a way to make students show up to class. I'm not sure what to recommend, but the number of people in class toward the end of the semester shrunk by a great deal." Another student commented, "I didn't really like it when we had a group discussion day and a group leader didn't show up." In short, student engagement from the experimental section remained lively because of the continuity in attendance, whereas engagement in the control class diminished over time.

The classroom dynamics of the control class were fairly typical for one of my standard introductory classes, and feedback from most students was positive. There was a noticeable difference in the energy and depth of conversation within the control class, however, compared to the experimental class. It was harder for me to get students to respond to questions and talk with other classmates during group discussions. Often in the experimental section, students participated in vibrant class discussions. Such enthusiasm occurred less often in the control section, likely because of poor attendance or failure to comply with the reading assignment. When the vast majority of students in the experimental section attended class every day having completed the readings, it became routine for students to share ideas or questions related to assigned material and daily exams. This excitement never took hold in the control class to the same degree even though the two sections nearly mirrored one another.

It is difficult to gauge the extent that students complied with the readings assigned for the classes. Two methods suffice in measuring the approximate compliance rate, though. One approach is to simply ask students to raise their hands if they did or did not do the assigned reading. Some students will respond honestly, but often they are reluctant to signal their failure to read for class. A more effective method is to implement in-class quizzes on reading material with questions directly related to the concepts in the text (Hatteberg and Steffy 2013). Therefore, a second layer of strength of the design of daily exams is that I was able to get an ongoing snapshot of the approximate degree to which students in the class were arriving to class having read the material and prepared to respond to questions related to it. Based on the accuracy and strength of many of the students' exam responses in the experimental section, I would estimate that between 80 and 90 percent of students who were in attendance on any given day had read a significant portion of the assigned chapters or articles. At the end of the semester, these students anonymously reported in their course evaluation that they complied with the assigned readings at a high rate largely because they were expected to arrive to class prepared on a daily basis. Students expressed in the evaluation that the combination of daily written exams and the incentive for reading compliance were the class's strongest features and, in general, provided highly positive assessments of their experience with daily testing. Not only did most claim to comply with readings, but they also valued the ability to connect their reading to an immediate outcome in the class. It was difficult for me to get a sense of what the reading compliance rate was in the control section because there was no daily accountability structure built into the class. Attendance declined weekly, and many students were silent throughout the semester, so there were fewer opportunities for me to "check in" with them. Students from the controls section also did not voluntarily provide comments regarding reading compliance in evaluations.

\section{Student Perceptions of Course Outcomes}

A large percentage of students from both sections indicated that they were interested in sociology in general and the class lectures in particular. Many from each section also expressed they perceived learning a lot from the course and that their critical thinking skills improved. Despite the fact that students in the experimental section qualitatively appeared to hold more interest in their daily experience of being in class and participating in discussions, I did not find that frequent testing correlated with increased student perceptions of greater critical 
Table I. Students' Perceptions of Course Outcomes.

\begin{tabular}{|c|c|c|c|c|c|}
\hline \multirow[b]{2}{*}{ Survey Item } & \multicolumn{2}{|c|}{ Experimental $(n=34)$} & \multicolumn{2}{|c|}{ Control $(n=32)$} & \multirow[b]{2}{*}{ Significance } \\
\hline & M & SD & M & SD & \\
\hline \multicolumn{6}{|l|}{ Please rate your overall } \\
\hline Interest in class lectures ${ }^{a}$ & 4.67 & .64 & 4.34 & .94 & \\
\hline Satisfaction with the exams in this class ${ }^{b}$ & 3.85 & .36 & 3.44 & .72 & $*$ \\
\hline $\begin{array}{l}\text { Perception of the amount learned from } \\
\text { this course }\end{array}$ & 3.74 & .45 & 3.53 & .62 & \\
\hline \multicolumn{6}{|l|}{ Improvement of ... ${ }^{d}$} \\
\hline Critical thinking skills & 2.68 & .47 & 2.47 & .62 & \\
\hline Writing skills & 2.33 & .47 & 1.94 & .62 & $*$ \\
\hline
\end{tabular}

thinking skills, the amount they learned from the course, or their interest in lectures. Nevertheless, a statistically significant proportion of students within the experimental section were very satisfied with daily exams and perceived a great improvement in their writing skills compared to students from the control section (Table 1).

Students reinforced this perception when given the chance to comment on the "best aspects of the course" in their evaluations. Sixty-five percent of the students in the experimental section explicitly stated that the daily written exams were the feature they appreciated the most. In their survey of the course, more than 84 percent of them reported that they were "very satisfied" with the exams, and more than 14 percent reported feeling "somewhat satisfied." Students in the control section also had positive perceptions of their exams but not to the same degree. In their survey, 53 percent were "very satisfied," and 40 percent were "somewhat satisfied." Six percent of the students in this section were unsatisfied with the exams, and only one student stated that they considered the exams the best aspect of the course.

Students from the experimental section elaborated on a variety of reasons for why they preferred studying for and taking daily low-stakes exams compared to major high-stakes exams when they commented on the fairness and usefulness of tests and assignments in evaluations. Of particular interest, not a single student had a negative perception of the daily exam structure but instead voiced strong satisfaction in their assessment of frequent low-stakes exams. Even though students from the experimental section did not display a statistically significant greater perception of learning from the course as a whole compared to the control section, they qualitatively reported learning more from this type of examination. When provided the opportunity to comment on exams, more than 20 percent of students in the experimental section argued that they felt like they learned more through frequent low-stakes testing. One student response summed up this perception by stating, "I thought that the exams every class were really helpful in giving incentive to read the material as well as retain the material much better than in other courses." Students from the control class did not express the same types of sentiments regarding their overall satisfaction with the exams. In fact, few of these students even took the time to write anything regarding their experience with the exams during the semester at all, and none reported learning more from high-stakes exams. This qualitative difference perhaps reflects the fact that taking infrequent high-stakes exams is the norm and not particularly noteworthy.

\section{CONCLUSION}

There are some compelling explanations for the differences in student responses between the two classes, specifically with their perceived improvements in writing skills and overall satisfaction with exams. First, and perhaps most importantly, students who took daily exams received constant 
feedback, which is crucial for conceptual learning and improvement (Bransford, Brown, and Cocking 1999). When I distributed exams back to students on a daily basis, I included specific comments that let them know how and why they scored well or poorly and what they could do to make adjustments for future exams. This daily feedback provided students with maneuvering room for improvement, ways of thinking, and approaches to reading and writing over time that they might not receive otherwise. If a student performed poorly on a few exams in the experimental class, their final grade was not jeopardized, whereas in the control class, if a student performed poorly on one of the major exams their final grade was likely to be greatly affected. Indeed, students greatly appreciated having a dayto-day sense of how they were doing in the class and how they could make progress. For new or unprepared students, receiving a lot of feedback was a valuable experience that assisted in their transition to higher education.

It is also likely that the greater satisfaction with exams that students reported in the experimental class stemmed from the different studying techniques they employed over the semester. With daily exams, students did not have the option to procrastinate reading assigned material or cram their study. In the experimental section, students arrived prepared to discuss the assigned material because they were forced to read daily and their grade depended on it (Gabriel 2008). Without this built-in accountability, students often put off readings and crammed information right before a major deadline, thus reducing their ability to participate with their classmates or follow along with the information provided during lectures. When everyone came to class having read the material, however, there were more opportunities for students to interact in a meaningful and constructive way with one another and the lecture. When students began the class by responding in writing to questions, they had already generated thoughts that each could reference during class discussion.

Students in the experimental section also reported greater satisfaction with daily exams because of the reduced anxiety associated with low-stakes testing. It is common for students to experience a large amount of testing anxiety in classes that have only a small number of highstakes major exams (Gabriel 2008). Instructors are often unaware, though, of the extent to which it can detract from their engagement with class. Anxiety is amplified among underprepared students who comprise a sizable percentage of students in introductory classes. Those who are unaccustomed to both the defined or tacit norms of college can find integrating into courses and studying for major exams to be incredibly stressful and daunting (Weimer 2002). Simply put, many arrive to college without the experience, knowledge, or tools for how to succeed with tests. Removing or reducing high-stakes exams and replacing them to some degree with a variety of low-stakes exams, instructors also remove a large contributing factor to anxiety that inhibits student performance and enjoyment of the class. In course evaluations, many students expressed relief in not having to prepare for a major exam where their performance would have an enormous impact on their final grade. Free of these anxieties, students embrace new study skills and let the frequent testing operate as a tool to guide and improve performance.

There are also tradeoffs associated with frequent testing that must be taken into account. Perhaps the greatest concern that might dissuade an instructor from implementing daily written exams to their class is the enormous amount of time it takes to grade every day. I would devote somewhere between 80 and 120 minutes to grade 40 exams depending on the amount of feedback students needed on various issues related to writing composition and their articulation of sociological concepts. Over the entire semester, I spent approximately 45 hours grading exams for the experimental section compared to about 27 hours in the control section. This time required to grade may not be feasible for many instructors, especially those who teach very large introductory sections. Although instructors desire to implement the most effective pedagogical strategies into their classrooms, they also must consider the structural constraints they now face in many higher education settings. The combination of slashed state budgets, the declining percentage of full-time faculty, and expanding introductory class sizes simply means people are performing greater amounts of work for lower compensation (Lucal 2015). Additionally, full-time faculty find themselves committed to extensive research projects, service requirements, and various committees that all compete for their limited time. Therefore, most instructors are likely reluctant to adopt a testing method into their class if it will add a significant amount of labor to their already very busy workload.

Of course, in classes with larger enrollment numbers, instructors could modify the type of examination to match the size of the class. Written exams may not be feasible, so instructors could 
incorporate an exam format with a series of multiple choice or short answer questions. To speed up the examination process and automate grading, instructors could utilize more sophisticated testing devices such as personalized clickers for each student. In this case, daily exam questions could be projected for the entire class and students could use a purchased or rented clicker to select responses. Another option, similar to Pennebaker et al.'s (2013) approach, would be to implement daily online exams that students could work through using personal wifi-enabled laptops or tablets. With either of these methods, a computer can automatically generate student scores. These methods allow instructors to structure daily low-stakes testing into the classroom without spending additional time grading. Approaches like these are also likely to secure high attendance and reading compliance rates. Relying on automated testing techniques, though, does not require students to respond to questions in writing. Consequently, many of the beneficial features of written examinations that I have presented in this study would be eliminated, as well as extensive feedback from the instructor.

In these regards, there are limitations to this study that could be addressed in future research. Additional studies could test how students respond to and perceive of a variety of different frequent low-stakes exam formats. It would be useful to know which types of frequent exams, such as written, short answer, or multiple choice, are most effective in producing strong learning outcomes and how they are perceived by students. It would also be helpful to know if frequent exams scheduled only weekly or biweekly had the same effect as daily exams. Additionally, this study did not take into account how the time of day in which the course is offered could factor into student perceptions of examinations. ${ }^{1}$ Future studies could test the relationship between class time and frequent testing.

These limitations, however, should not detract instructors of introductory sociology from implementing frequent low-stakes exams to some degree in their courses. A central finding from this study is that students are receptive to this model and prefer continuous engagement with reading and assessment. Frequent examination creates the conditions that hold students accountable to be present and engaged with class, comply with assigned reading, and retrieve what they have learned regularly. Therefore, I support a wider application of frequent low-stakes testing within introductory sociology courses because of these overlapping positive outcomes.

\section{ACKNOWLEDGMENTS}

The author would like to thank the faculty in the Sociology and Anthropology Department at Indiana University South Bend for their support and the editor and reviewers for their helpful comments.

\section{EDITOR'S NOTE}

Reviewers for this manuscript were, in alphabetical order, Leslie Elrod, Judson Everitt, Sarah Hatteberg, and Kody Steffy.

\section{NOTE}

1. The control class in this study met at 8:30 AM, and the experimental class at 2:30 PM.

\section{REFERENCES}

Atkinson, Maxine P., and Kathleen S. Lowney. 2016. In the Trenches: Teaching and Learning Sociology. New York: W.W. Norton.

Bangert-Drowns, Robert L., James A. Kulik, and ChenLin C. Kulik. 1991. "Effects of Frequent Classroom Testing." The Journal of Educational Research 85(2):89-99.

Barr, Robert B., and John Tagg. 1995. "From Teaching to Learning - A New Paradigm for Undergraduate Education." Change 27(6):12-26.

Bransford, John D., Ann L. Brown, and Rodney R. Cocking, eds. 2000. How People Learn: Brain, Mind, Experience, and School: Expanded Edition. Washington, DC: National Academy Press.

Brocato, Joe. 1989. "How Much Does Coming to Class Matter? Some Evidence of Class Attendance and Grade Performance." Educational Research Quarterly 13(3):2-6.

Brown, Peter C., Henry L. Roediger III, and Mark A. McDaniel. 2014. Make It Stick: The Science of Successful Learning. Cambridge, MA: The Belknap Press of Harvard University Press.

Burchfield, Colin M., and John Sappington. 2000. "Compliance with Required Reading Assignments." Teaching of Psychology 27(1):58-60.

Carey, Benedict. 2014. How We Learn: The Surprising Truth about When, Where, and Why It Happens. New York: Random House.

Cepeda, Nicholas J., Edward Vul, Doug Rohrer, John T. Wixted, and Harold Pashler. 2008. "Spacing Effects in Learning: A Temporal Ridgeline of Optimal Retention." Psychological Science 19(11):1095-102.

Doubleday, Justin. 2013. "Most Students Are Unprepared for College, SAT Results Show." The Chronicle of Higher Education. Retrieved June 15, 2015 (http://chronicle.com/article/Most-Students-AreUnprepared/141919/).

Dunlosky, John, Katherine A. Rawson, Elizabeth J. Marsh, Mitchell J. Nathan, and Daniel T. 
Willingham. 2013. “Improving Students' Learning with Effective Learning Techniques: Promising Directions from Cognitive and Educational Psychology." Psychological Science in the Public Interest 14(1):4-58.

Elbow, Peter. 1997. "High Stakes and Low Stakes in Assigning and Responding to Writing." New Directions for Teaching and Learning 69(Spring):5-13.

Friedman, Paul, Fred Rodriguez, and Joe McComb. 2001. "Why Students Do and Do Not Attend Classes: Myths and Realities." College Teaching 49(4):124-34.

Gabriel, Kathleen F. 2008. Teaching Unprepared Students: Strategies for Promoting Success and Retention in Higher Education. Sterling, VA: Stylus Publishing.

Graham, Steve, and Michael Hebert. 2010. Writing to Read: Evidence for How Writing Can Improve Reading. A Carnegie Corporation Time to Act Report. Washington, DC: Alliance for Excellent Education.

Greenwood, Nancy, and Jay Howard. 2011. First Contact: Teaching and Learning in Introductory Sociology. Lanham, MD: Rowman and Littlefield.

Graurholz, Liz, Joanna Eisele, and Nicole Stark. 2013. "Writing in the Sociology Curriculum: What Types and How Much Writing Do We Assign." Teaching Sociology 34(1):5-22.

Greenlaw, Steven A. 2003. "Using Writing to Enhance Student Learning in Undergraduate Economics." International Review of Economics Education 1(1):61-70

Halpern, Diane, and Milton Hakel. 2003. "Applying the Science of Learning to the University and Beyond: Teaching for Long-term Retention and Transfer." Change 35(July/August):36-41.

Hatteberg, Sarah J., and Kody Steffy. 2013. "Increasing Reading Compliance of Undergraduates: An Evaluation of Compliance Methods." Teaching Sociology 41(4):346-52.

Jacobs, Lucy Cheser, and Clinton I. Chase. 1992. Developing and Using Tests Effectively. San Francisco: Jossey-Bass.

Kling, Nathan, Denny McCorkle, Chip Miller, and James Reardon. 2005. "The Impact of Testing Frequency on Student Performance in a Marketing Course." Journal of Education for Business 81(2):67-72.

Kika, Frank M., Tim F. McLaughlin, and J. Dixon. 1992. "Effects of Frequent Testing of Secondary Algebra Students." Journal of Educational Research 85(3):159-62.

Kuh, George, Jillian Kinzie, John Schuh, Elizabeth Whitt, and Associates. 2007. Student Success in College: Creating Conditions that Matter. San Francisco: Jossey-Bass.

Leamnson, Robert. 1999. Thinking about Teaching: Developing Habits of Learning with First Year
College and University Students. Sterling, VA: Stylus.

Leeming, Frank C. 2002. "The Exam-a-day Procedure Improves Performance in Psychology Classes." Teaching of Psychology 29(3):210-12.

Lucal, Betsy. 2015. "2014 Hans O. Mauksch Address: Neoliberalism and Higher Education: How a Misguided Philosophy Undermines Teaching Sociology." Teaching Sociology 43(1):3-14.

Marshall, P. 1974. "How Much, How Often?" College and Research Libraries 35(6):453-56.

McDaniel Mark A., Pooja K. Agarwal, Barbie J. Huelser, Kathleen B. McDermott, and Henry L. Roediger, III. 2011. "Test-enhanced Learning in a Middle School Science Classroom: The Effects of Quiz Frequency and Placement." Journal of Educational Psychology 103(2):399-414.

Pennebaker, James W., Samuel D. Gosling, and Jason D. Ferrell. 2013. "Daily Online Testing in Large Classes: Boost College Performance while Reducing Achievement Gaps." PLOS ONE 8(11):1-6.

Quitadamo, Ian J., and Martha J. Kurtz. 2007. "Learning to Improve: Using Writing to Increase Critical Thinking Performance in General Education Biology." CBE Life Sciences Education 6(2):140-54.

Rosenfeld, Rachel Ann. 1978. "Anxiety and Learning" Teaching Sociology 5(2):151-66.

Sanoff, Alvin P. 2006. "A Perception Gap Over Students' Preparation." The Chronicle of Higher Education. Retrieved August 1, 2015 (http://chronicle.com/article/ A-Perception-Gap-Over/31426).

Siadat, M. Vali, Paul M. Musial, and Yoram Sagher. 2008. "Keystone Method: A Learning Paradigm in Mathematics." PRIMUS: Problems, Resources, and Issues in Mathematics Undergraduate Studies 18(4):337-48.

Self, James. 1987. "Reserve Readings and Student Grades: Analysis of a Case Study." Library \& Information Science Research 9(1):29-40.

Wankat, Phillip C. 2002. The Effective, Efficient Professor: Teaching, Scholarship, and Service. Boston: Allyn and Bacon.

Weimer, Maryellen. 2002. Learner-centered Teaching. Five Key Changes to Practice. San Francisco: Jossey-Bass

Zipp, John. 2007. "Learning by Exams: The Impact of Two-stage Cooperative Tests." Teaching Sociology 35(1):62-76.

\section{AUTHOR BIOGRAPHY}

Zachary Schrank is an assistant professor in the Department of Sociology and Anthropology at Indiana University South Bend. His research interests include consumer culture and sustainable consumption practices. 